\title{
Tobacco industry response to a risk assessment of environmental tobacco smoke
}

\author{
Lisa A Bero, Stanton A Glantz
}

\begin{abstract}
Objective-To analyse the tobacco industry's response to the US Environmental Protection Agency (EPA) draft risk assessment of environmental tobacco smoke (ETS) and compare it to the response of the EPA's Science Advisory Board. To examine the peer review status of the literature cited to support criticisms of the risk assessment. Method-A content analysis of all submissions received by the EPA, analysis of all literature cited in the submissions and classification by topic and whether or not the literature was peer reviewed.

Results - Sixty-four percent $(69 / 107)$ of submissions received by the EPA claimed that the conclusions of the draft were invalid and, of these, $71 \%(49 / 69)$ were submitted by tobacco industry-affiliated individuals. The specific arguments presented by commentors affiliated with the industry differed qualitatively from those of the Science Advisory Board and were supported by the selective citation of nonpeer reviewed literature. Compared to tobacco industry-affiliated reviewers, the risk assessment cited more references on ETS (32\% vs. $15 \%)$ and fewer nonrefereed publications $(27 \%$ vs. $37 \%)(p<$ 0.001).
\end{abstract}

Conclusion - The majority of comments that were critical of the risk assessment were submitted by tobacco industryaffiliated reviewers. The critical comments differed in content from the Science Advisory Board Report and were more often (compared to the draft EPA report) supported by non-peer reviewed references.

(Tobacco Control 1993; 2: 103-113)

\section{Introduction}

Public policies to regulate exposure to environmental hazards are generally based on formal risk assessments prepared through a process open to scrutiny and comment from the public and industries that might be affected by regulation of their product. It is sometimes difficult to determine whether or not an industry's response to a regulatory policy is a valuable scientific contribution to the risk assessment or mere advocacy of the industry's economic interest. The tobacco industry has been subject to increasing restrictions of its product because of growing evidence that cigarette smoke is an air pollutant. ${ }^{1-5}$ The industry's response has been multi-faceted, consisting of advertising, political advocacy, funding research, and "smokers' rights" campaigns. ${ }^{6-10}$ Despite these efforts by the industry, there has been an increasing awareness of the health effects of tobacco, including the effects of tobacco smoke on non-smokers. Restrictions on where people can smoke have led to decreases in the amount of tobacco people consume. ${ }^{11-13}$

Recently, the public and the tobacco industry have been offered the opportunity to respond with scientific comments to a risk assessment of environmental tobacco smoke (ETS) conducted by the US Environmental Protection Agency (EPA) entitled "Health effects of passive smoking: assessment of lung cancer in adults and respiratory disorders in children" ("the draft risk assessment") ${ }^{14}$ The draft risk assessment concluded that ETS causes lung cancer in adults and respiratory problems in children. The draft had significant policy implications since its approval led to a decision to classify ETS as a Group A (known human) carcinogen and has accelerated the trend towards smoking restrictions in workplaces and public places. The draft was open to technical comment from June 25 to October 1 , 1990. The draft was also reviewed by the EPA's Science Advisory Board (SAB) to provide an outside, expert assessment of its scientific accuracy. A summary of the public comments was provided to the SAB. The EPA revised and updated the document following the public comment period and SAB review. This study compares the content of the comments submitted by persons affiliated with the tobacco industry to the comments by the SAB.

The only study to evaluate the quality of scientific data presented by the tobacco industry in response to a government report on ETS was conducted by the New Zealand Department of Health. ${ }^{15}$ Its analysis of the New Zealand Tobacco Institute's submission in response to the New Zealand Department of Health's report on ETS, ${ }^{16}$ found that the Tobacco Institute submitted an incomplete, selective and distorted analysis of the scientific data. Specifically, the New Zealand Department of Health concluded that the submission: reviewed less than $40 \%$ of the refereed scientific literature published since the US Surgeon General's report on ETS; cited mainly unrefereed research for post-1986 studies; ignored scientists' defence of their work, 
presenting criticisms of the work as if they had not been answered; ignored most articles on child health and ETS; accorded small studies as much merit as large studies; and denied the validity of pooling results of existing studies (meta-analysis) to obtain sufficient numbers for analysis. ${ }^{15}$

This study examines all submissions received by the EPA during its public comment period to determine if submissions from the US tobacco industry presented a pattern of argument and citation similar to that presented by the New Zealand Tobacco Institute. We tested the hypothesis that comments which opposed the conclusions of the draft risk assessment were no more likely to be submitted by individuals affiliated with the tobacco industry than others. We also compared the editorial review policies for the citations in critical comments to the policies for citations in the draft risk assessment to assess the scientific rigor of these two sets of citations.

\section{Methods}

\section{DATA SOURCES}

All submissions received during the public comment period on the draft risk assessment "Health effects of passive smoking: assessment of lung cancer in adults and respiratory disorders in children" (Docket number EPA/600/6-90/006A), and the SAB Report were obtained from the EPA.

\section{CHARACTERISATION OF SUBMISSIONS RECEIVED} DURING THE PUBLIC COMMENT PERIOD

Each submission was classified as either supporting, neutral to, or opposing the EPA's tentative conclusion that ETS causes lung cancer in adults and respiratory problems in children. A total of 107 submissions were received by the EPA. (Due to space limitations, these are unable to be fully referenced in this paper. Complete references are available through the National Auxiliary Publications Service. $\left.{ }^{\star}\right)$ Of these, $64 \%(69 / 107)$ were critical of the draft risk assessment while $31 \%$ $(33 / 107)$ supported the conclusion of the risk assessment and $1 \%(2 / 107)$ were neutral (eg, pointed out a typographical error) and were

* See NAPS document no. 05016 for 16 pages of supplementary material. This material contains the names and addresses of authors of all comments submitted to the EPA. When references are made to the comments throughout the text, * indicates that the specific references to individual comments are given in the NAPS document. Order from NAPS c/o Microfiche Publications, P.O. Box 3513, Grand Central Station, New York, NY 10163-3513, USA. Remit with your order, not under separate cover, $\$ 7.75$ (US funds on a US bank only) for photocopies or $\$ 4.00$ for microfiche. Outside the US and Canada, add postage of $\$ 4.50$ for photocopies or $\$ 1.75$ for microfiche. Institutions and organisations may order by purchase order; however, there is a billing and handling charge for this service of $\$ 15$, plus any applicable postage. excluded from any further analyses. Three comments were missing from the materials received from EPA.

We determined whether or not the author of a comment was affiliated with the tobacco industry. An affiliation as defined in this study means that the reviewer had a financial or other interest in the tobacco industry. An affiliation does not mean that the reviewer was biased or supported the position of the tobacco industry that ETS is not harmful to health. For example, a tobacco industry-affiliated (TIA) reviewer could have submitted a comment to the EPA which supported the conclusions of the draft. A reviewer was categorised as being affiliated if he or she, 1) disclosed in the written comment that he or she was a paid consultant to the tobacco industry, 2) received grant funding from the tobacco industry, 3) appeared at least twice at tobacco industrysponsored symposia, 4) testified as an expert witness in support of the tobacco industry during legal proceedings, or 5) was on the Board of Directors of a tobacco company or the Tobacco Institute. Sources used to determine tobacco industry affiliations were, 1) the submissions themselves, 2) curriculum vitae accompanying the submissions, 3 ) proceedings of tobacco industry-sponsored symposia, and 4) transcripts from legal proceedings.

PATTERNS OF ARGUMENT PRESENTED BY TIA REVIEWERS AND THE SAB

A content analysis of each comment was made to place the criticisms of the draft into one of six categories: 1) study selection, 2) epidemiologic methods, 3) statistical analysis, 4) bias and confounding, 5) exposure estimates, and 6) other. We compared the comments by TIA reviewers to the comments presented by the SAB. We determined the peer-review status of the literature used to support the arguments of the TIA reviewers. We examined the concordance between the criticisms of TIA reviewers and the criticisms of the SAB. For example, if both the TIA reviewers and the SAB commented that the risk assessment analysis omitted studies, but the TIA reviewers suggested including more epidemiological studies which did not find an association between ETS and ill health, while the SAB suggested including more animal toxicology studies which demonstrated an association between active smoking and lung cancer, we concluded that the TIA reviewers and the SAB were not concordant. For each category of criticism, the TIA reviewers' argument, the peer-review status of the literature used to support the argument, and the SAB's conclusion regarding the argument, if any, is described.

COMPARISON OF PEER REVIEW STATUS AND TOPICS OF CITATIONS IN THE RISK ASSESSMENT TO THOSE OF CITATIONS IN SUBMISSIONS CRITICAL OF THE RISK ASSESSMENT

We tested the hypothesis that there was no difference in the proportion of peer-reviewed 
literature cited in the EPA risk assessment and the proportion cited in the critical comments. The citations were classified according to their published peer-review policies into five categories of peer-reviewed literature and 16 categories of non-peer-reviewed literature ${ }^{\star \star}$ (see Appendix 1). Multiple citations were not counted. We also compared the literature cited in the draft risk assessment to that cited by the critical reviewers with regard to focus on the health effects of ETS. For this analysis, we classified each citation into one or more of six categories: 1) children (health effects of ETS and/or other variables in children), 2) confounding variables (health effects of variables other than ETS, eg, car exhaust, radon), 3) ETS (health effects), 4) exposure (ETS exposure measurement or critiques of measurement), 5) statistics (description or critique of statistical techniques or study design, such as meta-analysis), and 6) other (eg, mechanisms of carcinogenesis, risk assessment methods in general)

\section{STATISTICS}

All comparisons were done with chi-square analysis of contingency tables.

$\star \star$ We used two resources to search for the literature cited: 1) the University of California Periodicals Database and 2) the Technical Information Center, Office on Smoking and Health, Centers for Disease Control and Prevention, Atlanta, Georgia. The Periodicals Database consists of 799136 periodical titles representing 1194200 holdings from the University of California, the California State Library, the California State Universities, Stanford University, University of Southern California, the Getty Center for the History of Art and the Humanities, the Center for Research Libraries, and the California Academy of Sciences. The Technical Information Center compiles the annual Bibliography on Smoking and Health, keeps a computerised database which includes journal articles and other materials related to tobacco, and produces the annual Report of the Surgeon General on the health consequences of smoking. Staff at the Technical Information Center are available to do specialised literature searches.

\section{Results}

CHARACTERISATION OF SUBMISSIONS RECEIVED DURING THE PUBLIC COMMENT PERIOD

Seventy-one percent of critical comments came from TIA authors, while $100 \%$ of supportive comments were submitted by individuals with no disclosed affiliations to the tobacco industry (table 1). The proportion of TIA reviewers who submitted critical comments $(100 \%$, 49/49) was significantly greater than the proportion of non-TIA reviewers who submitted critical comments $(38 \%, 20 / 53)(p=0.001$, Chi-square analysis). Of the 49 reviewers who satisfied our criteria for tobacco industry affiliation, $33(67 \%)$ disclosed on their submission to the EPA that they were writing their response at the request of the tobacco industry.

\section{PATTERNS OF ARGUMENT PRESENTED BY TIA} REVIEWERS AND THE SAB

Table 2 lists the criticisms presented by TIA reviewers and whether or not the $S A B$ made the same criticisms. Overall, the SAB was in concordance with 4 out of 50 criticisms presented by TIA reviewers and was not in concordance with 27 criticisms made by TIA reviewers. The SAB did not mention 19 criticisms made by TIA reviewers. The most frequent criticisms and the literature cited to support them are described below.

\section{Criticisms of study selection}

Twenty TIA reviewers stated that the literature database used for the draft risk assessment was incomplete and excluded negative studies ${ }^{\star}$. Submissions from TIA reviewers cited unsupported opinion, such as letters-tothe-editor, editorials, or discussions at conference proceedings, as evidence that should have been considered by the EPA rather than peer-reviewed publications. For example, the Tobacco Institute's submission cited papers from symposia 32 times, one unpublished article, one letter-to-the-editor, one editorial, seven peer-reviewed journal articles, and one unidentified citation ${ }^{\star}$.

Thirteen TIA reviewers recommended that two negative studies be included in the analysis regardless of their source, quality, or country

Table 1 Number and percentage of total critical and supportive comments submitted to the EPA according to tobacco industry affiliation of the commentor

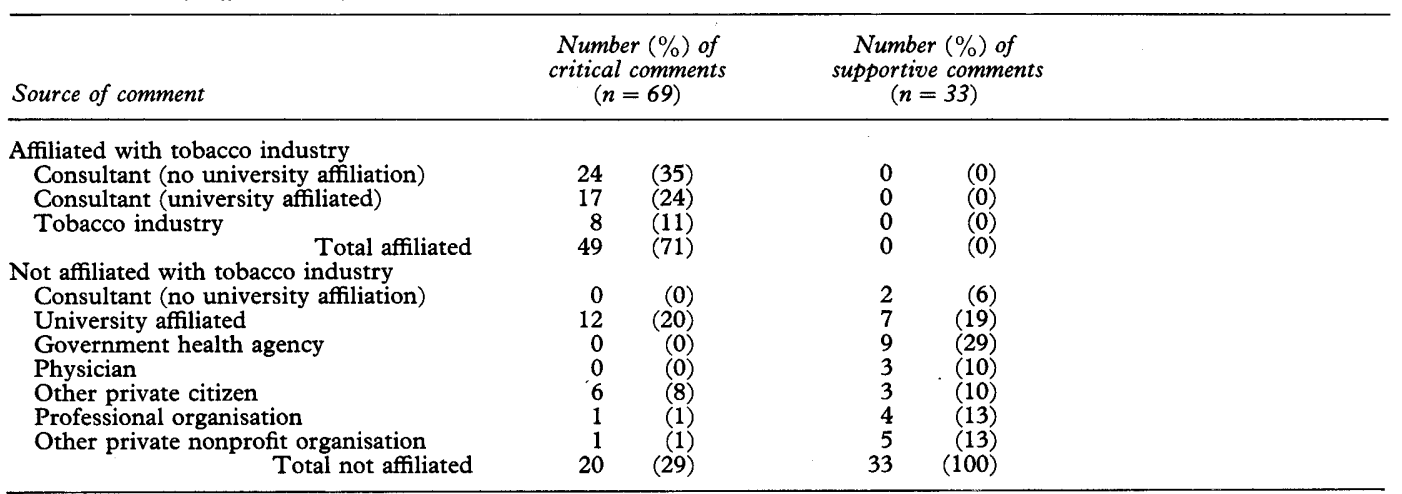


Table 2 Arguments presented by tobacco industry-affiliated (TIA) reviewers ${ }^{\star}$

\begin{tabular}{|c|c|c|}
\hline Argument & $\begin{array}{l}\text { No. of mentions in } \\
\text { TIA comments }\end{array}$ & $\begin{array}{l}T I A \text { comments \& } S A B \\
\text { report concordant }\end{array}$ \\
\hline $\begin{array}{l}\text { STUDY SELECTION } \\
\text { Studies inappropriately included or excluded } \\
\text { : Negative studies were excluded } \\
\text { : Studies were excluded due to publication bias } \\
\text { Only US studies should have been included } \\
\text { : Studies of males should have been included } \\
\text { - Study results were reported selectively }\end{array}$ & $\begin{array}{r}20 \\
15 \\
14 \\
3 \\
2\end{array}$ & $\begin{array}{l}\text { no } \\
\text { not mentioned } \\
\text { no } \\
\text { not mentioned } \\
\text { not mentioned }\end{array}$ \\
\hline $\begin{array}{l}\text { Criticisms of Hirayama study } \\
\text { Criticisms of the study remain unanswered } \\
\text { There was a reporting bias } \\
\text { - The data are not representative }\end{array}$ & $\begin{array}{r}13 \\
4 \\
3\end{array}$ & $\begin{array}{l}\text { not mentioned } \\
\text { not mentioned } \\
\text { not mentioned }\end{array}$ \\
\hline $\begin{array}{l}\text { EPIDEMIOLOGICAL METHODS } \\
\text { The criteria for scientific proof have not been met }\end{array}$ & 3 & not mentioned \\
\hline $\begin{array}{l}\text { Criticisms of methodology } \\
\text { - Recall bias is a problem } \\
\text { - Use of questionnaires is problematic }\end{array}$ & $\begin{array}{l}4 \\
3\end{array}$ & $\begin{array}{l}\text { not mentioned } \\
\text { not mentioned }\end{array}$ \\
\hline $\begin{array}{l}\text { Criticisms of epidemiology } \\
\text { Epidemiology should not be relied upon } \\
\text { - Epidemiology criticised in general } \\
\text { Results are meaningless when strength of association is low }\end{array}$ & $\begin{array}{l}9 \\
7 \\
5\end{array}$ & $\begin{array}{l}\text { no } \\
\text { not mentioned } \\
\text { no }\end{array}$ \\
\hline $\begin{array}{l}\text { No animal data exist to support an association between ETS and lung } \\
\text { cancer }\end{array}$ & 14 & no \\
\hline $\begin{array}{l}\text { STATISTICAL ANALYSIS } \\
\text { Statistics used in individual studies were inappropriate }\end{array}$ & 9 & no \\
\hline $\begin{array}{l}\text { Criticisms of meta-analysis } \\
\text { : Cannot be used when studies have inconsistent results } \\
\text { Cannot be used when individual studies have flaws } \\
\text { Cannot be used with nonhomogeneous studies } \\
\text { Meta-analysis was used inappropriately } \\
\text { Should have used weight of evidence instead } \\
\text { - Method criticised in general } \\
\text { - Wald method criticised }\end{array}$ & $\begin{array}{r}16 \\
16 \\
11 \\
8 \\
6 \\
4 \\
2\end{array}$ & $\begin{array}{l}\text { no } \\
\text { not mentioned } \\
\text { not mentioned } \\
\text { no } \\
\text { no } \\
\text { no } \\
\text { not mentioned }\end{array}$ \\
\hline $\begin{array}{l}\text { BIAS AND CONFOUNDERS } \\
\text { The problem of misclassification was not dealt with adequately } \\
\text { Criticisms of diagnostic data }\end{array}$ & 12 & no \\
\hline $\begin{array}{l}\text { All diagnoses were not confirmed by histopathology } \\
\text { Lung cancers detected were of inconsistent histological type } \\
\text { Childhood diagnoses have different meanings }\end{array}$ & $\begin{array}{l}8 \\
7 \\
1\end{array}$ & $\begin{array}{l}\text { yes } \\
\text { not mentioned } \\
\text { not mentioned }\end{array}$ \\
\hline $\begin{array}{l}\text { Confounding variables were not adequately controlled } \\
\text { - Confounders mentioned in general } \\
\text { Environmental } \\
\text { Socioeconomic } \\
\text { Cultural/Lifestyle } \\
\text { Diet } \\
\text { - Genetic } \\
\text { Viral infections }\end{array}$ & $\begin{array}{r}19 \\
9 \\
8 \\
6 \\
4 \\
4 \\
3\end{array}$ & $\begin{array}{l}\text { no } \\
\text { no } \\
\text { no } \\
\text { no } \\
\text { no } \\
\text { no } \\
\text { no }\end{array}$ \\
\hline $\begin{array}{l}\text { EXPOSURE ESTIMATES } \\
\text { Criticisms of exposure estimates } \\
\text { - Cotinine/nicotine are not valid markers } \\
\text { Spousal smoking is not a good estimate of ETS exposure } \\
\text { No valid marker for ETS exposure exists } \\
\text { The composition of ETS is not known } \\
\text { Background exposure estimates are invalid } \\
\text { ETS is a minor indoor air pollutant } \\
\text { The distribution of ETS is not known } \\
\text { - The nose and lung defend the body from ETS }\end{array}$ & $\begin{array}{r}16 \\
13 \\
7 \\
7 \\
6 \\
5 \\
3 \\
2\end{array}$ & $\begin{array}{l}\text { no } \\
\text { no } \\
\text { no } \\
\text { no } \\
\text { yes } \\
\text { not mentioned } \\
\text { not mentioned } \\
\text { not mentioned }\end{array}$ \\
\hline $\begin{array}{l}\text { ADDITIONAL CRITICISMS } \\
\text { Biological plausibility } \\
\text { Mainstream smoke and ETS differ } \\
\text { : Exposure to ETS is too low to have health effects } \\
\text { General arguments against plausibility } \\
\text { - Mainstream smoke does not cause cancer }\end{array}$ & $\begin{array}{r}10 \\
9 \\
9 \\
2\end{array}$ & $\begin{array}{l}\text { no } \\
\text { not mentioned } \\
\text { no } \\
\text { no }\end{array}$ \\
\hline $\begin{array}{l}\text { Criticisms of dose response estimate } \\
\text { No dose-response relationship exists } \\
\text { Linear extrapolation to low doses is invalid } \\
\text { - The relative potency approach is not valid }\end{array}$ & $\begin{array}{l}9 \\
6 \\
2\end{array}$ & $\begin{array}{l}\text { no } \\
\text { no } \\
\text { yes }\end{array}$ \\
\hline The EPA did not follow its own guidelines for risk assessment & 5 & yes \\
\hline
\end{tabular}

* TIA comments are the comments submitted by tobacco industry-affiliated reviewers. Concordance between TIA comments and the SAB report was rated as "yes" if the two presented exactly the same argument, "no" if they presented opposing arguments, or "not mentioned" if the SAB report did not make the argument put forth by TIA reviewers.

of origin, ${ }^{17,18}$ or argued that the risk assessment should be based only on studies conducted in the US. * The SAB believed that data from all studies should be utilised in evaluating whether exposure to ETS increases the risk of lung cancer. ${ }^{19}$

The SAB did identify some deficiencies in the literature reviewed in the draft report. In contrast to the TIA reviewers, the SAB suggested inclusion of peer-reviewed publications rather than non-peer reviewed litera- ture. The SAB also suggested the inclusion of positive studies which found an association between ETS and health effects rather than negative studies. The SAB concluded that the draft EPA report failed to consider all studies on the toxicology of ETS, the evidence on active smoking and lung cancer, and the effect of ETS on respiratory disease in children, but stated that including these additional studies would strengthen, not weaken, the conclusion that ETS is a Group A carcinogen. ${ }^{19}$ 
Seventeen TIA reviewers* suggested that certain studies be removed from the EPA's analysis, especially Hirayama's original 1981 study linking ETS to lung cancer. ${ }^{20}$ To support this suggestion, four letters disputing the conclusions of Hirayama's paper linking involuntary smoking to cancer were cited. .1-24 $^{2}$ Only the EPA risk assessment and one TIA reviewer ${ }^{\star}$ cited Hirayama's published response to these criticisms. ${ }^{25}$ Two TIA reviewers ${ }^{\star}$ claimed that the EPA failed to consider the criticisms of the Hirayama study that have been published since 1986. These criticisms consist entirely of articles or panel discussions from sponsored symposia. ${ }^{26-37}$ The SAB did not criticise the EPA's use of the Hirayama study. ${ }^{19}$

\section{Criticisms of epidemiologic methods}

Nineteen TIA reviewers argued that the criteria for scientific proof had not been met by the risk assessment.* They denounced the reliance on epidemiological studies, criticising epidemiological survey methods and arguing that epidemiology is a poor and imperfect science. If references were cited to support these arguments, they were usually general reviews of the discipline. More often, TIA reviewers stated opinion, rather than referencing a critique of methodology. $\star \star \star$ The SAB approved the use of epidemiologic studies in the EPA risk assessment, but stated that additional chapters addressing the physics and chemistry of ETS, its relation to mainstream smoke, and the exposure of various populations to ETS would strengthen the conclusions of the draft. ${ }^{19}$

The draft was criticised by 14 TIA reviewers for considering epidemiologic data rather than animal toxicology data on the premise that toxicology is a more definitive science than epidemiology. ${ }^{\star}$ References to tobacco industry-sponsored symposia, a progress report, and one publication which could not be located were the only citations used to support the claim that no animal inhalation studies have reported adverse effects of ETS. ${ }^{38-44}$ The final report of a project funded by the Council for Tobacco Research (a tobacco industryfunded group) which concluded that active smoking does not cause cancer in rodents was also used to argue that adverse effects of ETS were not biologically plausible. ${ }^{45}$ In contrast, the EPA risk assessment referenced peerreviewed journal articles which stated that tobacco smoke inhalation induces carcinomas

$\star \star \star$ For example, one reviewer stated, "Epidemiological studies have more difficulty than experimental studies in achieving a level of significance strong enough to be considered proof". “ "In an epidemiological investigation we are not studying facts, but only responses to questions". $\star$ One reviewer preferred to attack epidemiologists themselves, rather than the discipline: "Epidemiologists are often biased in favor of finding positive results and of giving causal interpretations to such findings" and "reluctant to accept criticisms (by, for example, a statistician) about their findings". * in hamsters. ${ }^{46,47}$ The SAB did not identify the lack of animal toxicology data as a flaw in the draft risk assessment. The SAB pointed out that the carcinogenicity of tobacco smoke is not based on long-term animal studies, which are negative, but on epidemiologic studies of lung cancer and smoking in humans. ${ }^{19}$

\section{Criticisms of statistical analyses}

TIA reviewers criticised the statistical methods used in individual papers that were evaluated for the draft risk assessment. Nine submissions suggested that one statistical test be replaced by another, but the test in question was never central to the argument in the EPA risk assessment.* The criticism of 34 TIA reviewers focused on the risk assessment's choice of meta-analysis to combine the results of several epidemiological studies to obtain a single risk estimate. ${ }^{\star}$ Literature cited to support the argument against meta-analysis consisted of general review articles or editorials on meta-analysis, which neither supported nor refuted specifically the studies on ETS, and letters-to-the-editor (without citing the responses to the letters) critiquing metaanalysis and the effects of ETS on children. ${ }^{48,49}$ The SAB report concluded that meta-analysis "is an appropriate tool to summarize the epidemiological studies investigating the risk of ETS". ${ }^{19}$

Five TIA reviewers argued that the strength of association of ETS with adverse health effects calculated from the meta-analysis was too low to warrant classification as a Group A carcinogen. * However, the EPA risk assessment established a lower bound of 1.26 for a relative risk of $1.41 .{ }^{14}$ The SAB emphasised that a low risk from a hazard to which a large number of people are exposed can lead to a significant number of preventable deaths. ${ }^{19}$

\section{The problems of bias and confounding}

The EPA risk assessment addressed the methodological problem of misclassification bias (eg, coding smokers as exposed nonsmokers) and made a downward adjustment of the relative risk estimates to correct for misclassification. Twelve TIA reviewers either ignored or found fault with the EPA's adjustment and cited literature that shows that misclassification increases the estimated relative risk, while failing to cite literature which shows that misclassification can also lower it.* Eight TIA reviewers suggested methods from an unpublished paper, letters-to-the-editor, and tobacco industry-sponsored symposia to adjust for misclassification, instead of the method used by the EPA risk assessment, which was based on a peer-reviewed paper and used previously by the National Research Council in its evaluation of ETS. ${ }^{2,50-56 \star}$ The SAB concluded that misclassification was considered in detail in the draft risk assessment and that appropriate corrections were made. ${ }^{19}$ Sixteen TIA reviewers suggested that diagnoses of lung cancer might have been overestimated because not all diagnoses were 
confirmed by histology. ${ }^{\star}$ The SAB acknowledged this potential bias, but suggested that diagnoses of lung cancer might also be underestimated if an actual lung cancer was incorrectly classified as some other diagnosis. ${ }^{19}$

A criticism levied by 36 TIA reviewers was that the draft failed to consider adequately potential confounding variables that could cause lung cancer in adults and respiratory disorders in children. ${ }^{\star}$ Nineteen TIA reviewers mentioned confounders in general, while others mentioned specific confounders described in table 2 . The majority (91\%, $237 / 260$ ) of the papers cited on confounders were peer reviewed and included publications describing associations between lung cancer and occupation, diet, or pet bird ownership. The SAB stated that "Important potential confounders of the ETS-lung cancer relationship were addressed in the report.... The potential main confounders included in these adjusted analyses were age and surrogates for confounding factors, including education and social class. As for other potential confounders of the ETS-lung cancer relationship, including occupation, radon exposure, and diet, there is no way to evaluate their importance as confounders or to adjust for them, since virtually none of the studies contain information on them". 19

\section{Criticism of ETS exposure measurements}

Thirty-six TIA reviewers refuted ETS exposure estimates by claiming that ETS cannot be reliably measured, that spousal smoking (which was used to define exposure groups in most epidemiological studies) does not accurately indicate ETS exposure, that cotinine and nicotine are not reliable markers for ETS exposure, and that ETS distribution in the body is not understood (table 2). * Criticism of spousal smoking estimates was based primarily on symposia and references to papers on questionnaire methodology. ${ }^{57}$ The EPA risk assessment cited a peer-reviewed journal article that validated self-reported smoking behaviour data, while a TIA reviewer claimed that the risk assessment should have cited a chapter in a book which used a non-validated questionnaire to determine that university students underreported their smoking. ${ }^{58,59}$ TIA reviewers also argued that spousal smoking estimates were irrelevant because exposure at home could not be extrapolated to exposure at other sites. They attacked the work of Repace and Lowrey, published in a peerreviewed journal, which estimated the number of deaths in the US due to ETS exposure, and failed to cite Repace and Lowrey's earlier peerreviewed work and responses to criticism. ${ }^{60-63}$ The TIA reviewers listed "numerous scientific articles" criticizing this study, but in fact, the "articles" consist of two symposia, one letterto-the-editor, two editorials and one peerreviewed paper. ${ }^{64-69}$ Citations from industrysponsored symposia and the National Research Council report on ETS were also used to support the reviewers' contention that there is no reliable measure for ETS exposure. ${ }^{2,70-72}$
After considering the limitations of ETS exposure measurements, the SAB concluded that ETS exposure can be estimated and that "spousal smoking status seems to be a reasonable method of identifying people with greater, versus lesser, ETS exposure".19

\section{Additional criticisms}

Twenty-three TIA reviewers suggested that adverse health effects of ETS are not biologically plausible for a variety of reasons, including that actual exposure to ETS is too low to have any biological effect, that mainstream smoke and ETS differ in chemical composition, and that the specific cancercausing agent in mainstream smoke is unknown and might not be contained in ETS.* The SAB concluded that the chemical composition and particulate sizes of mainstream smoke and ETS were sufficiently similar to "directly imply carcinogenicity of ETS". ${ }^{19}$ The TIA reviewers' claims were again based primarily on papers published in symposia, while the SAB conclusion was based on peerreviewed literature. ${ }^{73,74}$

Thirteen TIA reviewers argued that no dose-response relationship for the health effects of ETS exists and that extrapolation of a dose-response effect is invalid. ${ }^{\star}$ TIA reviewers argued against the well-accepted theory that the lower limit of exposure necessary for carcinogenicity is not known. The SAB commented that "determination of the doseresponse effect of ETS based on the epidemiologic studies of Hirayama would be most valuable, "but did not say whether or not a dose-response relationship existed. ${ }^{19}$

One criticism of the EPA risk assessment did not assess the science upon which the assessment based its conclusion, but the governmental procedure used to assess risk. Seven TIA reviewers argued that the risk assessment did not follow the EPA's own risk assessment guidelines. $^{75 \star}$ The SAB stated that the risk assessment guidelines, which were designed to address a single chemical compound, were not directly applicable to ETS. They concluded that the risk assessment of ETS was "fully consistent with the risk assessments that [the EPA has] done for many other carcinogens ". ${ }^{19}$

\section{CRITICISMS BY NON-TIA REVIEWERS}

Thirty-three of the non-TIA reviewers commented that the draft was a thorough and balanced review of the scientific literature on ETS and that the conclusions were justified by the data presented. Reviewers not affiliated with the tobacco industry did criticize some aspects of the draft. They suggested that the EPA should include an additional section on the effect of ETS on coronary artery disease, that the report should establish the magnitude of risk of ETS relative to other environmental hazards, that the evidence linking childhood ETS exposure and ETS was stronger than suggested in the report, that the EPA's definition of bias should be clarified, and that the report should include additional discussion of



$\because$,

$-$

5

$\sim$



$\rightarrow$

$=$

$\rightarrow$

$+$

$\checkmark$

$=$

$-$

$\%$

$\rightarrow$

$y$

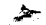

$\Rightarrow$

.

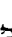

$x-$

;

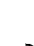

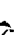

$\rightarrow$

$-$

$=$

$x$

$\div$

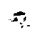

$y$

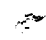

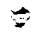

$y$

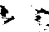


socioeconomic status as a confounding factor. Non-TIA reviewers suggested that a peerreviewed paper which found an association between ETS and disease be added to the risk assessment. ${ }^{76}$ The SAB agreed that the evidence on health effects of ETS in children was stronger than suggested in the report and suggested the addition of several peerreviewed references on children. The SAB also agreed that the definition of bias could be clarified. ${ }^{19}$

COMPARISON OF PEER REVIEW STATUS AND TOPICS OF CITATIONS IN THE RISK ASSESSMENT TO THOSE OF CITATIONS IN SUBMISSIONS CRITICAL OF THE RISK ASSESSMENT

Overall, submissions critical of the risk assessment cited four times as many individual references $(n=1620)$ as the draft risk assessment $(n=391)$. Only $3 \%$ of the citations could not be located. The proportion of peerreviewed material cited by the EPA risk assessment differed from that cited by critical reviewers $(73 \%$ vs. $63 \%, p=0.0002)$ (table 3 ). The pattern of topics of citations in the risk assessment differed from citations in the critical comments ( $p=0.0001$, table 4$)$. The risk assessment cited a greater proportion of papers examining the health effects of ETS, whereas the critical comments cited a larger proportion of papers on potential confounding variables. The papers on confounding variables did not assess the health effects of ETS or control for ETS exposure. The risk assessment and critical comments cited similar proportions of papers on respiratory health in children, ETS exposure measurements, statistical methods, and other topics.

\section{Discussion}

The strategy of criticizing the methodology of studies that have a potential impact on one's economic or political position is common to all industries. ${ }^{77}$ The strategy calls for framing one's reactions as a seemingly objective, scientific evaluation of the methodology used in the study. ${ }^{78}$ The tobacco industry's specific approach in response to the EPA risk assessment was to criticize the draft's methodology by selectively citing the scientific literature that supported its position, rather than citing all the relevant literature. The TIA reviewers often cited unrefereed literature, such as symposia, editorials, and letters-to-the-editor, and they cited this material as though it were peer reviewed. The large number of critical comments on the draft risk assessment suggested on the surface that it was seriously flawed and that the evidence regarding the health effects of ETS remains controversial. However, the majority of the critical comments were submitted by reviewers affiliated with the tobacco industry. The pattern of argument and citation displayed in the TIA submissions was similar to that used by the Tobacco Institute of New Zealand in its rebuttal to the New Zealand Department of Health report on ETS. ${ }^{15}$ The

Table 3 Number and percentage of total citations in critical comments and EPA risk assessment by peer review status

\begin{tabular}{lrrrr}
\hline & \multicolumn{3}{c}{$\begin{array}{c}\text { Number (\%) cited } \\
\text { in critical comments } \\
(n=1620)\end{array}$} & $\begin{array}{c}\text { Number (\%) } \\
\text { cited in draft risk } \\
\text { assessment } \\
(n=391)\end{array}$ \\
\hline Type of reference & & & & \\
Not peer reviewed & 13 & $(1)$ & 1 & $(0)$ \\
Abstract & 95 & $(6)$ & 18 & $(5)$ \\
Book & 4 & $(0)$ & 2 & $(0)$ \\
Dissertation & 35 & $(2)$ & 4 & $(1)$ \\
Editorial & 9 & $(1)$ & 3 & $(1)$ \\
Environmental journal & 14 & $(1)$ & 3 & $(1)$ \\
Government report & 63 & $(4)$ & 11 & $(3)$ \\
Letter-to-the-editor & 3 & $(0)$ & 0 & $(0)$ \\
Medical/scientific journal & 9 & $(1)$ & 0 & $(0)$ \\
News & 74 & $(5)$ & 13 & $(3)$ \\
Other & 9 & $(1)$ & 1 & $(0)$ \\
Submitted publication & 220 & $(14)$ & 39 & $(10)$ \\
Symposium proceeding & 14 & $(1)$ & 1 & $(0)$ \\
Tobacco trade publication & 40 & $(3)$ & 9 & $(2)$ \\
Unknown & 602 & $(37)$ & 105 & $(27)$ \\
$\quad$ Total not peer reviewed & & & & \\
Peer reviewed & 26 & $(2)$ & 3 & $(1)$ \\
Review in review journal & 53 & $(3)$ & 17 & $(4)$ \\
Consensus report & 1 & $(0)$ & 0 & $(0)$ \\
Law journal & 61 & $(4)$ & 16 & $(4)$ \\
Environment journal & 877 & $(54)$ & 250 & $(64)$ \\
Medical/scientific journal & 1018 & $(63)$ & 286 & $(73)$ \\
$\quad$ Total peer reviewed & & & &
\end{tabular}

Table 4 Number and percentage of total citations in critical comments and EPA risk assessment by topic. (Percentages do not add up to 100 because topics were not mutually exclusive)

\begin{tabular}{lcccc}
\hline $\begin{array}{l}\text { Topic of } \\
\text { citation }\end{array}$ & $\begin{array}{c}\text { Number }(\%) \text { of citations } \\
\text { in critical comments } \\
(n=1620)\end{array}$ & $\begin{array}{c}\text { Number }(\%) \text { of citations in } \\
\text { draft risk assessment } \\
(n=391)\end{array}$ \\
\hline ETS & 235 & $(15)$ & 123 & $(32)$ \\
Confounders & 260 & $(16)$ & 12 & $(3)$ \\
Children & 259 & $(16)$ & 95 & $(24)$ \\
Exposure & 218 & $(14)$ & 53 & $(14)$ \\
Statistics & 134 & $(8)$ & 21 & $(5)$ \\
Other & 766 & $(47)$ & 248 & $(63)$ \\
\hline
\end{tabular}


comments from TIA reviewers and citations used to support them were in sharp contrast to the comments provided by the $\mathrm{SAB}$, a group of independent experts who also reviewed the draft. The SAB pointed out areas in which the risk assessment could be improved, but its criticisms tended to be more balanced than the TIA reviewers. For example, TIA reviewers stated that misclassification and diagnostic bias could only increase the estimated relative risk, while the SAB noted that these biases could serve to increase or decrease the relative risk.

Recently, several of the arguments presented by TIA reviewers in response to the risk assessment have been rebutted. ${ }^{79}$ These include the arguments that ETS is far less important than other indoor air pollutants; assessment of non-smokers' exposure to ETS is inadequate for risk assessment; markers for ETS in body fluids are not reliable indicators of ETS exposure; non-smokers' doses of ETS are too small to result in disease; smoking by a spouse is not a good surrogate for ETS exposure; most causes of lung cancer are unknown but include radon, diet, and genetics; most studies of passive smoking show a high correlation with adenocarcinoma and there is no correlation between adenocarcinoma and active smoking; and misclassification of smokers as non-smokers can entirely account for the observed risk of passive smoking.

The industry strategy of focusing criticism on individual studies, rather than the evidence as a whole, has been noted previously..$^{15,80-82}$ By identifying individual studies that should have been included or excluded in the risk assessment, the TIA reviewers attempted to show that the analysis was unbalanced. However, they often cited unsupported opinion, such as letters-to-the-editor, editorials, or discussions at meeting proceedings, as evidence that ETS is not harmful. TIA reviewers sometimes misrepresented the findings of individual studies. Several reviewers claimed that the risk assessment failed to consider a doctoral dissertation that found no effect of passive smoking on non-smokers. ${ }^{83}$ When an analysis of data from this study was published in the peer-reviewed literature, it actually showed a moderate association between ETS and lung cancer. ${ }^{76}$ Criticism of cotinine as a marker for ETS exposure centered around citation of the National Research Council report and the work of various authors who called for more research on biochemical markers. ${ }^{2}$ The TIA reviewers misrepresented literature describing how methods of ETS exposure measurement can be incrementally improved by using it to suggest that currently available measures of ETS are invalid and should not be used at all.

TIA reviewers attempted to create an unattainable "standard of scientific proof" by failing to accept epidemiological models of causality and rejection of the null hypothesis. This tactic is identical to one that the industry has used for decades in contending that there is a continuing scientific "controversy" as to whether or not active smoking harms smokers. ${ }^{84}$
A frequent criticism of the draft risk assessment was that it ignored the literature on potential confounding factors that can contribute to lung cancer or respiratory problems in children. Although most of the literature cited to support the argument on confounders was peer reviewed, the papers cited did not usually include ETS exposure as a variable and, therefore, were not directly relevant to the EPA analysis. (For example, a paper might examine the association between socioeconomic class and lung cancer, but would not include ETS exposure as a variable in the same study.) We found that the draft risk assessment cited the available literature that assessed the effects of both ETS and confounders. Since the potential number of confounders is unlimited in a human study, it is important to identify the major factors, as the risk assessment did, and determine their impact on the reported outcome. The EPA decided to conduct the risk assessment without waiting for data on the relative contributions to disease of every possible confounder related to ETS, and the SAB report concurred with this decision.

The analysis of the scientific literature used to support specific arguments of the TIA reviewers reveals that the reviewers based their comments on non-peer-reviewed literature to a greater degree than did the EPA risk assessment. Competitive peer review appears to be associated with scientific rigor. $^{85}$ In addition, a published review of the literature on ETS which rated the quality of studies according to epidemiological criteria, found that the majority of papers which ranked low on the criteria were derived from non-peerreviewed sources. ${ }^{86}$ The citation of non-peerreviewed literature by reviewers affiliated with the tobacco industry suggests that the industry was attempting to refute the scientific evidence published in peer-reviewed publications with research or opinion of inferior quality. In addition, the non-peer-reviewed material cited by the critical reviewers was not acknowledged as such and criticisms included in letters-tothe-editor were cited without citing investigators' responses to the letters.

The tobacco industry appears to be producing publications which can be used to support its contention that ETS is not harmful to health, including pseudo- or quasi-scientific booklets, pamphlets, editorials, and letters-tothe-editor refuting the harmful effects of ETS. ${ }^{82}$ In addition, four of the symposia cited in the critical comments explicitly stated that they were sponsored, at least in part, by the tobacco industry. ${ }^{87-90}$ This material was heavily cited by TIA reviewers.

The majority of respondents who supported the risk assessment were not paid for their critiques (two were consultants), while the majority of critical commentators had some financial connection to the tobacco industry in the form of grant funding, honoraria, payment for expert testimony, or employment by the industry. As financial support can present a potential conflict of interest, the source of funding for comments should be disclosed and 




considered as they are reviewed. In the current study, only $67 \%$ of the affiliations with the tobacco industry were disclosed. One limitation of this study is that we relied only on written sources to identify affiliations with the tobacco industry; therefore, we might have underestimated the number of commentors

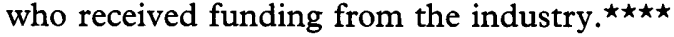

The tobacco industry has used the comments as part of its public relations campaign to refute the dangers of ETS. The tobacco industry prepared excerpts of criticisms of the risk assessment and released them at a press conference in $1990 .{ }^{91}$ These excerpts have been circulated to local legislators where smoking restrictions were being considered in California. In addition, letters-to-the-editor and editorials in local newspapers where smoking restrictions were being considered have cited the TIA reviewers comments as if they represented the EPA's position. ${ }^{92,93}$ One letter stated that, according to EPA Docket No. 600-6-90-006A, "over 50 scientists speak out against the overblown health issue of ETS". ${ }^{92}$ None of this press material acknowledges that the majority of the comments came from sources affiliated to the tobacco industry, or that these statements did not represent EPA policy.

On 22 July 1992, the SAB approved the final draft of the EPA risk assessment of the health effects of ETS ${ }^{94}$ The final draft identifies ETS as a Group A carcinogen that causes 3000 lung cancer deaths annually in the US. The draft also concludes that ETS causes increased respiratory symptoms, middle ear disease, and reduced lung capacity in children. Although the EPA was not required by law to respond to the public submissions described in this paper, a reading of the final document suggests that all comments were carefully considered in revising the draft. $^{95}$ By responding to the tobacco industry criticisms, as well as to the criticisms of other reviewers and the SAB, the EPA scientific staff produced a stronger document. However, the involvement of the tobacco industry in the critical comments and the literature cited to support the comments detracted from the scientific value of their criticism. The price to the public has been that the sheer volume of industry documents requiring consideration probably slowed down release of the final report and, perhaps, reduced the resources that EPA devoted to other work. Tobacco industry activities might also have drawn public attention to the report and thereby increased public interest in and awareness of the dangers of ETS.

As the regulation of ETS exposure continues

$\star \star \star \star \star$ A letter sent to the EPA on 8 July 1992 supports our supposition that we underestimated the number of critical reviewers who received funding from the tobacco industry. The critical commentators who sent the letter acknowledged that "we inadvertently neglected to clearly indicate that we are both consultants to the Tobacco Institute and that our submission was made at the request and expense of the Tobacco Institute" (Philip Witorsch, written communication, 8 July 1992). to be an issue, the tobacco industry can be expected to persist in using the tactics outlined in this paper at the local, national, and international level to refute the independent scientific findings regarding the health effects of ETS. Policymakers concerned with limiting the effects of ETS exposure should be informed about these tactics in order to evaluate fairly the conclusions of scientific consensus documents on ETS.

This study was supported by funds provided by the Cigarette and Tobacco Surtax Fund of the State of California through the Tobacco-Related Disease Research Program of the University of California under award 2KT0072 (LAB) and award 1RT 520 (SAG)

We would like to thank George Alexeef, Charles Becker, Alison Galbraith, Thomas Novotny, Drummond Rennie, and Donald Shopland for their comments on this manuscript and Adrienne Brazelton for administrative help.

\section{Appendix}

Literature that was peer reviewed was classified as:

1) Consensus report - a report compiled by a panel of scientific experts and peer reviewed before publication;

2) Environmental journal article - an article from a journal which focussed on environmental issues, but not issues related to health, and had a published peer-review policy (eg, Environ Int, Environ Sci Technol);

3) Law journal article-an article from a law journal that had a published peer-review policy;

4) Medical/scientific journal article-an article from a medical or scientific journal that had a published peer-review policy; and,

5) Review article - an article from a medical or scientific journal which did not present original research, but reviewed the literature on a topic. Review articles were further classified as derived either from peer-reviewed scientific or medical journals (eg, Appl Occupat Environ Hyg, N Engl $f \mathrm{Med}$ ) or from peer-reviewed specialty journals which publish only review articles (eg, Nutr Rev, Semin Respir Med, Compr Ther).

Literature that was not peer reviewed was classified as:

1) Abstract - an abstract from a conference proceeding;

2) Advertisement - an advertisement from a magazine or newspaper;

3) Book - an entire book, text book, book chapter, or monograph;

4) Dissertation - a doctoral dissertation;

5) Editorial - an opinion piece containing no data which was published in a newspaper, magazine, medical journal, etc.;

6) Environmental journal article - an article from a journal which focussed on environmental issues, but not issues related to health, and did not have a published peer-review policy (eg, Environ Technol Lett, $\mathcal{\exists}$ Environ Econ Man);

7) Government Report - a report issued by a government agency, but not prepared by a scientific panel (eg, "Risk Assessment in the Federal Government: Managing the Process", National Research Council, 1983);

8) Law journal article - an article from a law journal that did not have a published peerreview policy;

9) Letter-to-the-Editor - a letter published in peerreviewed medical, scientific, or environmental journals, but not subjected to the same type of competitive peer-review as articles published in the journals;

10) Medical/scientific journal article-an article 
from a medical or scientific journal that did not have a published peer-review policy;

11) News clipping - a clipping from a magazine, newspaper, or a press release;

12) Radio transcript-a published transcript from an interview broadcast on radio;

13) Submitted publication - a manuscript which had been submitted to a journal for review, but had not yet been accepted;

14) Symposium - a paper which was presented at a meeting and published in either a medical journal or book. The proceeding did not contain a published peer-review policy;

15) Tobacco trade publication-article in a trade magazine published by the tobacco industry; and,

16) Unknown - if the citation could not be located in the University of California library system or with the aid of the Technical Information Center, Office on Smoking and Health, Centers for Disease Control and Prevention, Atlanta, Georgia, USA.

1 International Agency for Research on Cancer (IARC Monograph). Evaluation of carcinogenic risk of chemicals to humans : tobacco smoking, Vol. 38. Lyon: IARC, 1986: 163-314.

2 National Research Council. Environmental tobacco smoke: measuring exposures and assessing health effects. Washington, DC: National Academy Press, 1986.

3 US Department of Health and Human Services. The health consequences of involuntary smoking : a report of the Surgeon General. Washington, DC: DHHS, 1986 . (DHHS Publication No (CDC) 87-8398.)

4 Glantz SA, Parmley WW. Passive smoking and heart disease-epidemiology, physiology and biochemistry. Circulation 1991; 83: 1-12.

5 Steenland K. Passive smoking and the risk of heart disease. 7 Am Med Assoc 1992; 267: 94-9.

6 Marshall E. Tobacco science wars. Science 1987; 236: 250-1

7 Marshall E. Tobacco industry does slow burn over EPA advisor. Science 1991; 250: 203

8 Ernster V, Burns D. A rebuttal to the tobacco industry's paper, "Cigarette smoke and the nonsmoker." I Public Health Policy 1984; 5(3): 368-75.

9 Warner KE, Goldenhar LM, McLaughlin CG. Cigarette advertising and magazine coverage of the hazards of advertising and magazine coverage of the
smoking. $N$ Engl f Med 1992; 326: 305-9.

10 Davis RM. Current trends in cigarette advertising and avis RM. Current trends in cigarette adver
marketing. $N$ Engl f Med 1987; 316: 725-32.

11 Becker DM, Conner HF, Waranch HR, Stillman F, Pennington L, Lees PS et al. The impact of a total ban on smoking in the Johns Hopkins Children's Center. $\mathcal{F} \mathrm{Am}$ Med Assoc 1989; 262(6): 799-802.

12 Marshall E. Involuntary smokers face health risks. Science 1986; 234: 1066-7.

13 Stillman FA, Becker DM, Swank RT, Hantula D, Moses $\mathrm{H}$, Glantz $\mathrm{S}$ et al. Ending smoking at the Johns Hopkins medical institutions: An evaluation of smoking prevalence and indoor air pollution. $\mathcal{f} A m$ Med Assoc 1990; 264(12): 1565-9.

14 US Environmental Protection Agency. Health effects of passive smoking: assessment of lung cancer in adults and respiratory disorders in children. Washington D.C.: Indoor Air Division, Office of Atmospheric and Indoor Air Air Division, Office of Atmospheric and Indoor Air
Programs, Office of Air and Radiation, USEPA, 1990. Programs, Office of Ai
(EPA $/ 600 / 6-90 / 006 A$.)

15 New Zealand Department of Health, prepared by J. Reinken. Through the smokescreen $-A$ critique of environmental tobacco smoke: A review of the literature by the Tobacco Institute of New Zealand. Wellington: NZDH, 1990.

16 New Zealand Department of Health, Creating smokefree environments. Wellington: NZDH, 1988.

17 Shimizu H, Morishita M, Mizuno K, Masuda T, Ogura Y, Santo $M$ et al. A case control study of lung cancer in nonsmoking women. Tohoku $\mathcal{f}$ Exp Med 1988; 154: 389-96.

18 Sobue T, Suzuki T, Nakayama N, Inubushi T, Matsuda $M$, Doi $O$ et al. Association of indoor air pollution and passive smoking with lung cancer in Osaka. fap $\mathcal{J}$ Cancer Clin 1990; 36: 329-33.

19 US Environmental Protection Agency. Report of the Indoor Air Quality and Total Human Exposure Committee : review of the Office of Research and Development Draft Report, "Health effects of passive smoking: assessment of lung cancer in adults and respiratory disorders in children." Washington, DC: EPA, 1991. (EPA/600/6-90/006A.)

20 Hirayama T. Non-smoking wives of heavy smokers have a higher risk of lung cancer: A study from Japan. $B M \mathcal{F}$ 1981 ; 282: 183-85.

21 Macdonald EJ. BMF 1981; 283 : 915.

22 Kornegay HR, Kastenbaum MA. BMF 1981; 283 : 914.

23 Harris JE, DuMouchel WH. BMF 1981; 283: 914.

24 Mantel N. BMF 1981; 283: 914.
25 Hirayama T. BMF 1981; 283 : 916.

26 Letzel H, Uberla K. Meta-analysis on passive smoking and lung cancer. In: Kasuga $\mathrm{H}$, ed. Indoor air quality. New York: Springer-Verlag, 1990: 317-22.

27 Letzel $\mathrm{H}$ et al. Meta-analysis on passive smoking and lung cancer; effects of study selection and misclassification of
exposure. In: Perry R, Kirk PW, eds. Indoor and ambient air quality. London: Selper Ltd, 1988: 293-302.

28 Bacon-Shone J. The use of statistics to evaluate the leve and effect of indoor air pollution. In: Lunau F, Reynolds $\mathrm{GL}$, eds. Indoor air quality and ventilation. London Selper Ltd, 1990: 11-4.

29 Uberla K, Ahlborn W. Passive smoking and lung cancer: A reanalysis of Hirayama's data. In: Kasuga H, ed. Indoor air quality. New York: Springer-Verlag, 1990: 333-41.

30 Layard M, Viren J. Assessing the quality of a Japanese cohort study. In: Bieva et al. eds. Present and future of indoor air quality. New York: Elsevier Science Publishing Co., 1989: 177-80.

31 Layard $M$. Environmental tobacco smoke and cancer: The epidemiologic evidence. In: Ecobichon D, Wu J, eds. Environmental tobacco smoke: proceedings of the international meeting at McGill University 1989. Massachusetts: Lexington Books, 1990: 99-115.

$32 \mathrm{Mantel} \mathrm{N}$. What is the epidemiologic evidence for a passive smoking-lung cancer association? In: Kasuga $\mathrm{H}$, ed. Indoor air quality. New York: Springer-Verlag, 1990: 341-7.

33 Panel discussion on lung and other cancers. In: Ecobiochon $\mathrm{D}$, Wu J, eds. Environmental tobacco smoke: proceedings of the international symposium at McGill University 1989. Massachusetts: Lexington Books, 1990: 117-36.

34 Kilpatrick SJ, Viren J. Age as a modifying factor in the association between lung cancer in non-smoking women and their husbands' smoking status. In: Perry R, Kirk PW, eds. Indoor and ambient air quality. London: Selper Ltd, 1988: 195-202.

35 Kilpatrick SJ. Model specification effects in ETS/nutrition research. In: Kasuga $\mathrm{H}$, ed. Indoor air quality. New York: Springer Verlag, 1990: 256-71.

36 Kilpatrick SJ. An example of extra-poison variation suggesting an under-specific model. In: Bieva et al. eds. Present and future of indoor air quality. New York: Elsevier Science Publishing Co., 1989: 83-90.

37 Ahlborn W, Uberla K. Passive smoking and lung cancer: A reanalysis of Hirayama's data. In: Perry R, Kirk PW, eds. Indoor and ambient air quality. London: Selper, Ltd., 1989: 169-78.

38 Mohtashamipur E, ed. Proceedings of the international experimental toxicology symposium on passive smoke. Toxicol Lett 1987: 35 .

39 Adlkofer F, Scherer G, Wenzel-Hartung R. Exposure of hamsters and rats to sidestream smoke of cigarettes: Preliminary results of a 90 day inhalation study. In: Perry $\mathrm{K}$, Kirk PW, eds. Indoor and ambient air quality. London: Selper, Ltd., 1988: 252-8.

40 Adlkofer F, Scherer G, et al. Exposure to ETS and its biological effects. In: Bieva CJ, ed. Present and future of indoor air quality. New York, Elsevier Science Publishing Co., 1989: 186-96.

41 Haley N, Adams JD, Alsofon J, Hoffman D. Uptake of sidestream smoke by Syrian golden hamsters. Toxicol Lett 1987; 35: 83-8.

42 Haley N. Sidestream smoke uptake by Syrian golden hamsters in an inhalation bioassay. Indoor air 87, proc int conf indoor air quality and climate $1987 ; 2: 68-73$.

43 Haley N. Progress report Am Health Foundation. Washington, DC: USDHHS, 1988: 71-81. (USDHHS ington, DC: USDHHS, 1988: 71-81.
Publication No (PHS grant) CA29580-08.)

44 Dontenwill W. Arzneimittelforschung 1971; 21 : 142-3.

Henry C, Kouri R. Final report: chronic exposure of mice to cigarette smoke. New York: Field, Rich and Assoc., 1984.

46 Dontenwill W, Chavalier HJ, Harke HP, Lafrenz U, Reckzeh G, Schneider B. Investigations on the effects of chronic cigarette smoke inhalation in Syrian golden hamsters. I Natl Cancer Inst 1973; 51: 1781-1832.

47 Dontenwil W, Chevalier HJ, Harke HP, Klimisch HJ, Kuhnigle C, Reckzeh G et al. Studies on the effect on chronic cigarette smoke inhalation in Syrian golden hamsters and the importance of vitamin $A$ on morphological alterations after smoke exposure. $Z$ Krebsforsch 1977; 89: 145.

48 Eysenck HJ. An exercise in mega-silliness. Am Psycho 1978; (May): 517

49 Mantel N. Does passive smoking stunt the growth of children? Int F Epidemiol 1986; 15(3): 427-8.

50 Wald NJ, Nanchahal K, Thompson SG, Cuckle HS. Does breathing other people's smoke cause lung cancer? $B M \mathcal{F}$ 1986; 293: 1217-22.

51 Lee PN. Does breathing other people's tobacco smoke cause lung cancer? $B M{ }^{2} 1986 ; 293: 1503-4$.

52 Lee PN. Passive smoking and lung cancer association: A result of bias. Hum Biol 1987; 6: 517-24.

53 Lee P. An alternative explanation for the increased risk of lung cancer in nonsmokers. In: Perry R, Kirk PW, eds. Indoor and ambient air quality. London: Selper Ltd, 1988: $149-58$

54 Lee P. Misclassification as a factor in passive smoking. Lancet 1986; 2:867.

55 Lee PN. Misclassification of smoking habits and passive smoking. New York: Springer-Verlag, 1988.

56 Lee PN. Lung cancer and passive smoking: Association an artefact due to misclassification of smoking habits. Toxicol Lett 1987; 35: 157-62. 
57 Wynder EL, Kabat GC. Environmental tobacco smoke and lung cancer: A critical assessment. In: Kasuga $\mathrm{H}$, ed. Indoor air quality. New York: Springer-Verlag, 1990 5-15.

58 Akiba S, Kata H, Blot WJ. Passive smoking and lung cance among Japanese women. Cancer Res 1986; 46: 4804-7.

59 Saito AR. Smoking among young women in Japan. In: Aoki $M$, ed. Smoking and health 1987. New York: Elsevier Science Publishing Co., 1988: 517-9.

60 Repace JL, Lowrey AH. A quantitative estimate of nonsmokers' lung cancer risk from passive smoking. Environ Int. 1985; 11: 3-22.

61 Repace JL, Lowrey AH. Tobacco smoke, ventilation and indoor air quality. Science $1980 ; 208: 464-76$.

62 Repace JL, Lowrey AH. A rebuttal to criticism of the phenomenological model of nonsmokers' lung cancer risk from passive smoking. Environ Carcinogen Rev 1986; C4: 225-35.

63 Repace JL, Lowrey AH. Rebuttal to criticism of "A quantitative estimate of nonsmokers' lung cancer risk from passive smoking." Environ Int 1986;12:33-8.

64 Arundel A, Irwin T, Sterling T. Nonsmoker lung cancer risks from tobacco smoke exposure: an evaluation of risks from tobacco smoke exposure: an evaluation of Repace and Lowrey's phenomen
Sci Technol 1986; C4: 93-118.

65 Gross AJ. Risk assessments relating to environmental tobacco smoke. In: Ecobichon DJ, Wu JM, eds. En vironmental tobacco smoke: proceedings of the international meeting at McGill University. MA: Lexington Books, 1989: 293-302

66 Lebowitz $M$. The potential association of lung cancer with passive smoking. Environ Int 1986; 12: 3-9.

67 Balter NJ, Schwarts SL, Kilpatrick SJ, Witorsch P. Causa relationship between environmental tobacco smoke and lung cancer in non-smokers: A critical review of the literature. 79th Annual meeting of the Air Pollution Control Association, 1986.

68 Burch P. Health risks of passive smoking: problems of interpretation. Environ Int $1986 ; 12: 23-8$

69 Kilpatrick SJ. Environ Int 1986; 12: 29-31.

70 Koodfellow HD eton Int 1986; $12: 29-31$. Goodfellow HD et al. Assessing exposure to ETs. In:
Ecobichon DJ, Wu JM, eds. Environmental tobacco smoke : proceedings of the international meeting at McGill University. MA: Lexington Books, 1990: 53-68.

71 Reasor MJ. Biological markers in assessing exposure to ETS. In: Ecobichon DJ, Wu JM, eds. Environmenta tobacco smoke: proceedings of the international meeting at McGill University. MA: Lexington Books, 1990: 69-78.

72 DiNardi S. Exposure assessment for respirable suspended particles from $E T S$ in the indoor environment. Unpublished dissertation. Amherst: University of Massachusetts.

73 Eatough DJ. The chemical characterization of ETS Environmental tobacco smoke: proceedings of the international meeting at McGill University. MA: Lexington national meeting at

74 Balter NJ, Schwarts SL, Kilpatrick SJ, Witorsch P. Casual relationship between environmental tobacco smoke and lung cancer in non-smokers: A critical review of the literature. 79th Annual meeting of the Air Pollution Control Association, 1986

75 US Environmental Protection Agency. Workshop report on EPA guidelines for carcinogen risk assessment use of human evidence. Washington, DC: Eastern Group Report, June 1989.
76 Janerich DT, Thompson WD, Varela LR, Greenwald P, Chorost S, Tucci C et al. Lung cancer and exposure to tobacco smoke in the household. N Engl f Med 1990; 323(10): 632-36.

77 Rabin R. Warnings unheeded: A history of child lead poisoning. A f Pub Health 1989 ; 79(12): 1668-74.

78 Reinhart UE. Health manpower forecasting: The case of physician supply. In: Ginzberg E, ed. Health services research : key to health policy. Cambridge, MA: Howard research: key to health policy.

79 Repace JL, Lowrey AH. Passive smoking and the tobacco industry. Tobacco Control, 1993; 2: 56 .

80 Marshall E. Involuntary smokers face health risks. Science 1986; 234: 1066.

81 Glantz SA, Parmley WW. Dissent: passive smoking cause heart disease and lung cancer. $\mathcal{f}$ Clin Epidemiol 1992 45(8): 815 .

82 Chapman S, Borland R, Hill D, Owen N, Woodward S Why the tobacco industry fears the passive smoking issue. Int $\mathcal{F}$ Health Serv $1990 ; 20(3): 417-27$.

83 Valera L. Assessment of the association between passive smoking and lung cancer. PhD Dissertation, Yale University, 1987.

84 Slade J. An analysis of " $R$ J Reynolds' position paper on the health effects of smoking." Tobacco Products Lit igation Reporter 1986; 1(8): 5.97-5.105 (part I); 1986 1(9) 5.107-5.113 (part II)

85 Rennie D, ed. Guarding the guardians: A conference on peer review. $\mathcal{F} A M A 1986$; 256.

86 Spitzer W, Lawrence V, Dales R, Hill G, Archer MC, Clark $\mathrm{P}$ et al. Links between passive smoking and disease: best-evidence synthesis. Clin Invest Med 1990; 13(1): $17-42$.

87 Ecobichon DJ, Wu JM, eds. Environmental tobacco smoke: proceedings of the international meeting at McGill University. MA: Lexington Books, 1989.

88 Rylander $R$, ed Environmental tobacco smoke effects on the non-smoker: report from a workshop, Bermuda. the non-smoker: report from a work

89 Rylander R, Peterson Y, Lebowitz MD, eds. Assessing lowrisk agents for lung cancer: methodological aspects. Int $\mathcal{f}$ Epidemiol 1990; 19: suppl. 1.

90 Rylander R, Peterson Y, Snella M-C, eds. ETS - Environmental tobacco smoke: report from a workshop on effects and exposure levels at the University of Geneva. Eur F Respir Dis 1983; suppl. 133.

91 The Tobacco Institute. Science does not support draft document undergoing expert review. Washington, DC: The Tobacco Institute, Dec. 4, 1990

92 Angus DH. About smoke. Auburn $f 29$ Oct. 1991: A6.

93 Martin D. Smoking ban facts in doubt. Press Trib 9 Jan. 1992.

94 US Environmental Protection Agency. Respiratory health effects of passive smoking : lung cancer and other disorders. Washington DC: Indoor Air Division, Office of Atmospheric and Indoor Programs, Office of Air and

95 US Environmental Protection Agency. Respiratory health effects of passive smoking: lung cancer and other disorders. Washington, DC: Indoor Air Division, Office of Atmospheric and Indoor Programs, Office of Air and Radiation, USEPA, December 1992 (EPA/600/6 90/006F).

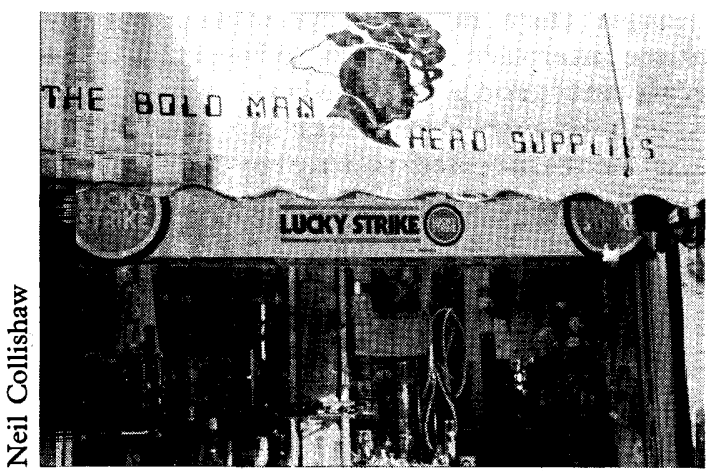

Lucky Strike advertised on the storefront of a "head shop" (where drug paraphernalia are sold) in Amsterdam 